\title{
Primary Central Nervous System Lymphoma Increasing Incidence and Poor Survival: A Finnish Population-based Analysis
}

\section{Inka Puhakka ( $\sim$ inka.puhakka@kuh.fi )}

Kuopio University Hospital: Kuopion yliopistollinen sairaala https://orcid.org/0000-0002-3387-9192

\section{Outi Kuittinen}

University of Eastern Finland - Kuopio Campus: Ita-Suomen yliopisto - Kuopion kampus

\section{Pekka Jäkälä}

Kuopio University Hospital: Kuopion yliopistollinen sairaala

\section{Hanne Kuitunen}

Oulu University Hospital District: Pohjois-Pohjanmaan Sairaanhoitopiiri

\section{Taina Turpeenniemi-Hujanen}

Oulu University Hospital District: Pohjois-Pohjanmaan Sairaanhoitopiiri

\section{Eila Sonkajärvi}

Oulu University Hospital District: Pohjois-Pohjanmaan Sairaanhoitopiiri

\section{Aino Rönkä}

Kuopio University Hospital: Kuopion yliopistollinen sairaala

\section{Tuomas Selander}

Kuopio University Hospital: Kuopion yliopistollinen sairaala

\section{Miika Korhonen}

Kuopio University Hospital: Kuopion yliopistollinen sairaala

\section{Research Article}

Keywords: pcnsl, primary central nervous system lymphoma, incidence, prognosis, survival, cancer registry

Posted Date: February 16th, 2021

DOI: https://doi.org/10.21203/rs.3.rs-231278/v1

License: (c) (1) This work is licensed under a Creative Commons Attribution 4.0 International License. Read Full License 


\section{Abstract}

\section{Purpose}

We report here the first population-based incidence rates and prognosis of primary central nervous system lymphoma (PCNSL) in Finland.

\section{Methods}

Finnish Cancer Registry data by histological diagnosis and tumor location (2007-2017) for cases with diffuse large B-cell lymphoma.

Results

During 2007-2017, 416 new cases of PCNSL were reported (202 males, 214 females). The average ageadjusted incidence in males vs. females for 2007-2009, 2010-2012, 2013-2015 and 2016-2017 was $0.57 / 100,000$ vs. $0.48 / 100,000$ person-years, $0.66 / 100,000$ vs. $0.55 / 100,000,0.53 / 100,000$ vs. $0.63 / 100,000$, and $0.76 / 100,000$ vs. $0.66 / 100,000$ respectively. The incidence was highest, $3.27 / 100,000$, among people aged 75-79 years. From 2007-2012 to 2013-2017, the 2-year age-adjusted survival rate increased from $36 \%$ to $41 \%$, and the 4 -year survival rates from $31 \%$ to $37 \%$. Among patients aged $70+$ years, the corresponding 2-year survival rates were $25 \%$ and $29 \%$, and the 4 -year survival rates $25 \%$ and $22 \%$.

Conclusion

Age-adjusted incidence of PCNSL increased from 0.57/100,000 (2007-2012) to 0.63/100,000 (20132017). The annual increase was $3.8 \%$ being among the highest reported in the world. The prognosis was poor, although a minor improvement in 4-year survival was found.

\section{What Is New?}

PCNSL incidence and survival rates in Finland have not been published previously. This study provides the first population-based estimates of PCNSL incidence and survival rates in Finland between 2007 and 2017. We discovered an increasing age-adjusted incidence of PCNSL in Finland, from 0.57/100,000 person-years for the period 2007-2012 to $0.63 / 100,000$ person-years for 2013-2017. The annual increase in PCNSL incidence was 3.8\% (95\% confidence interval [CI]: 0.7\% $-7.1 \%, p=0.016$ ) between 2007 and 2017. A higher PCNSL incidence in comparison to other Nordic and European countries was discovered.

\section{Introduction}

Primary central nervous system lymphoma (PCNSL) is a rare disease. However, several reports have described a growing incidence rate in Western countries [1-6]. The reasons for this increase are mostly unknown. A growing number of patients with immunosuppression may explain some proportion of this, 
but an increase is evident among immunocompetent people as well. Some environmental or lifestyle factors may explain these changes. It also seems that ethnic and genetic factors play a role, given that in the United States, the risk is different for the African American and Caucasian populations [1,7]. The literature examining Northern Europe describes incidence rates in Sweden of $0.26 / 100,000$ in the period 2000-2013 [8], in Norway of 0.18/100,000 during 1999-2003 [2], and in Denmark of 0.16/100,000 for 1983-1994 [3].

The prognosis for PCNSL has been poor, but several clinical trials with relatively short follow-up times have reported considerable progress in treatment outcomes among selected clinical trial populations [913]. However, this is in contrast to most of the population-based reports, which have demonstrated only minor improvement in long-term survival [1-6].

Here, we report Finnish Cancer Registry (FCR) [14] data concerning PCNSL incidence, age predisposition, and survival patterns for the years 2007-2017.

\section{Materials And Methods}

The data were extracted from Finnish Cancer Registry by histological diagnosis and tumor location. The data were ordered from the registry, and we received the completed calculations of the incidence and survival numbers, which we then analyzed. The research group did not take part in the collection of the data.

\subsection{Finnish Cancer Registry}

The FCR, established in 1952, is a nonprofit organization funded by the Cancer Society of Finland [16] and the Finnish Institute for Health and Welfare [17]. FCR receives cancer data from hospitals and other institutions providing treatment for cancer patients, health care professionals, pathology and cytology laboratories and Statistics Finland's cause of death data. Health care workers have a statutory obligation to report new cancer cases to the FCR. All cancer notifications since 2008 have been stored and coded by using ICD-0-3 codes (International Classification of Diseases for Oncology, Third Edition, WHO 2000, 1st revision 2013). FCR has a high level of coverage, which is shown to be over $95 \%$ for solid tumors [18]. FCR data do not include information considering possible underlying immunosuppression, such as HIV.

\subsection{Identification of PCNSL in FCR}

Inclusion criteria for the present study were histological or cytological verification of the diagnosis. To obtain reliable data, only cases of diffuse large B-cell lymphoma were included. For the present study, PCNSLs were defined as lymphomas located within the central nervous system (CNS; brain, eye, leptomeninges). Affision limited only to the eye was also accepted. The time period was limited to the years 2007-2017 because, during earlier periods, the histological subtyping was unreliable. 


\subsection{Statistical Analysis}

The incidence rates were calculated as the number of new cases per 100,000 person-years in each year and age-adjusted as the number of new cases per 100,000 person-years using Nordic standard population 2013 as a reference. $[19,20]$. Incidence rates were also reported by age groups and gender. The follow-up period was calculated from the date of the diagnosis to the date of the death or the end of the year 2017. A Poisson regression model was used to study annual incidence trends during 2007-2017 and to compare incidence rates in 2007-2012 for 2013-2017. For rate parameters the $95 \%$ confidence intervals $(95 \% \mathrm{Cl})$ were also reported. Survival analyses were calculated using Kaplan-Meier method for all the data and in different age and gender categories. Age-adjusted relative survival rates were calculated as the observed patient survival (that is, overall survival) corrected for the expected survival of an equivalent group in the general population with respect to age, sex and period. This is to eliminate the effect of general changes in population survival over time. In order to obtain most up-to-date picture, denoted period analysis was used for survival calculations [21,22]. P-values $<0.05$ were set to indicate statistically significant results.

\section{Results}

\subsection{Incidence}

During 2007-2017, 416 (214 females, 51\%) new PCNSL cases were reported (Figure 1). A total of 7\% of the patients were under 50 years old, $14 \%$ were $50-59,37 \%$ were $60-69,32 \%$ were $70-79$ years, and $10 \%$ were aged $80+$ years, as shown in Figure 2. We discovered an increasing age-adjusted incidence of PCNSL in Finland, from 0.57/100,000 (2007-2012) to 0.63/100,000 person-years (2013-2017). For the period 2007-2017, the annual increase in PCNSL incidence was 3.8\% (95\% Cl: $0.7 \%-7.1 \%, p=0.016)$.

The average age-adjusted incidence in males was $0.57 / 100,000$ for the period $2007-2009$ (0.54 to 0.60 ), $0.66 / 100,000$ for $2010-2012$ ( 0.40 to 1.00$), 0.53 / 100,000$ for $2013-2015$ ( 0.47 to 0.63 ), and $0.76 / 100,000$ for $2016-2017$ ( 0.76 to 0.76 ). Similarly, in females the age-adjusted incidence was $0.48 / 100,000$ for $2007-2009$ ( 0.47 to 0.49 ), $0.55 / 100,000$ for $2010-2012$ ( 0.50 to 0.65 ), $0.63 / 100,000$ for 2013-2015 (0.48 to 0.74 ), and $0.66 / 100,000$ for 2016-2017 (0.46 to 0.85). The incidence was highest, at $3.27 / 100,000$ person-years, among patients aged $75-79$.

\subsection{Survival}

Concerning both brain and eye lymphomas, the 2-year age-adjusted relative survival rate was 38\% (95\% $\mathrm{Cl} 33-44 \%)$. In cases with brain involvement only, the corresponding number was $33 \%$ (95\% $\mathrm{Cl} 28-38 \%$ ), as shown in Figure 3a. From the earlier period between 2007 and 2012 to the later period between 2013 and 2017 , the 2-year age-adjusted relative survival rate increased from $36 \%(95 \% \mathrm{Cl} 29-44 \%)$ to $41 \%$ 
(95\% Cl 34-48\%) for the whole population, including eye involvement also. The corresponding 4-year survival rates were $31 \%(95 \% \mathrm{Cl} 23-39 \%)$ and $37 \%$ (95\% $\mathrm{Cl} 29-44 \%)$, as shown in Figure 3b.

Older age was clearly related to an adverse disease outcome. The age-adjusted 2-year relative survival rate among patients aged 70+ years was 25\% (95\% Cl 15-37\%) between 2007 and 2012 and 29\% (95\%

$\mathrm{Cl} 19-40 \%)$ between 2013 and 2017. The corresponding 4-year survival rates were $25 \%(95 \% \mathrm{Cl} 14-39 \%)$ and $22 \%(95 \% \mathrm{Cl} 12-35 \%)$. Age-adjusted survival is displayed in Figure $3 \mathrm{c}$.

\section{Discussion}

Here, we report registry-based incidence rates and outcomes of PCNSL patients in Finland between 2007 and 2017. We discovered an increasing age-adjusted incidence, from $0.57 / 100,000$ for the period 20072012 to $0.63 / 100,000$ for 2013-2017. The latter is among the highest of reported incidence rates in the world $[4-6,8]$. While the prognosis for PCNSL still seems to be poor, during the study period, a trend to minor improvement in 4-year survival rates, from $31 \%$ in $2007-2012$ to $37 \%$ for $2013-2017$, was discovered.

\subsection{Incidence}

There are several registry-based reports describing an increasing incidence of PCNSL in countries with Western lifestyles [4-6,8]. In the United States, the Surveillance, Epidemiology, and End Results (SEER) database shows that the PCNSL incidence has increased from $0,1 / 100,000$ in the 1970 s to $0.4 / 100,000$ in 2013 [4]. In the most recent years, the increase seems to be flattening. This incidence growth has been greatest among people aged 70+, at a rate of 4.32/100,000 [23]. In Sweden, the overall incidence was $0.26 / 100,000$ between 2000 and 2013, with an average annual increase of $4 \%$ [8]. In a population-based study from the Netherlands, the PCNSL incidence increased from $0.30 / 100,000$ for the period 1989-1995 to $0.44 / 100,000$ for $2009-2015$. The incidence particularly increased in age groups over 60 years [6]. In Korea, the National Cancer Incidence Database shows that the average incidence of PCNSL was 0.17 between 1999 and 2009, with an annual rise of 9\% [5].

The incidence in Finland seems to be among the highest reported in the world, and there seems to be no flattening of the incidence curve. However, it should be noted that in this study, we had data from more recent time periods than the studies mentioned above, which may have caused some of this difference. The etiology behind this increase is unknown, but it is not explained by the population growth, which was minor during the study period, being around 200,000 . [24,25]. We believe that it is not explained by improved diagnostics, either. MRI scanning has already been a routine research method in Finland during the study period of 2007-2017 for patients suffering from neurological symptoms as well as for elderly patients. Moreover, in PCNSL, the symptoms progress rapidly, leading to patient deterioration, hospitalization, and diagnosis [26].

To evaluate whether the PCNSL incidence growth rate could potentially be explained by an increasing use of diagnostic imaging, we compared the incidence rates of PCNSL with the incidence rates of glioma in 
Finland. The incidence of glioma among the entire Finnish population increased from 6.32/100,000 person-years between 2007 and 2012 to 6.82/100,000 person-years between 2013 and 2017, according to data received from the FCR. During the study period of 2007-2017, the median annual increase in glioma was $1.2 \%$ (95\% Cl: $0.3 \%-2.3 \%)$. The PCNSL incidence growth rate was higher compared to gliomas but not statistically significant.

Immunosuppression increases the risk of PCNSL. From the FCR data, we were not able to get data about potential underlying HIV infection or other immunosuppression. However, we believe that the number of these patients is small. According to the Finnish Institute for Health and Welfare, between 2007 and 2017 , the HIV incidence in Finland varied from 146 to 187 cases per year (187 cases in 2007 and 158 cases in 2017) [27]. In Finland, all HIV patients are treated with effective highly active antiretroviral therapy (HAART), which further decreases the likelihood that the increase in PCNSL incidence could be explained by increased number of new cases with HIV.

This fact is further supported by detailed unpublished data regarding patient comorbidities from the Oulu University Hospital (OYS) district, which shows that among patients diagnosed between 2000 and 2018 , only 1 out of 112 PCNSL cases had a congenital immunosuppressive background, and there were no patients with a history of HIV or organ transplantations (unpublished data from Oulu University Hospital registry).

When analyzing the etiology behind these numbers, the difference in incidence rates between Finland and other Nordic countries is interesting. During corresponding time periods, the incidence in Finland was more than double the corresponding numbers of other Nordic countries. The genetic background of the Finnish people differs remarkably from the rest of Europe, and there are also variations in genetics between eastern and western Finns [28].

\subsection{Prognosis}

Worldwide, the prognosis for PCNSL has been dismal. Nevertheless, in recent years, several studies have reported considerable progress in treatment outcomes [9-13,29]. For example, in the International Extranodal Lymphoma Study Group-32 (IELSG-32), the 30-month progression-free survival rate in the group treated with MATRix regimen (methotrexate, cytarabine, thiotepa, and rituximab) was 49\%, compared with $23 \%$ of those treated with methotrexate-cytarabine alone and $30 \%$ of those treated with methotrexate-cytarabine plus rituximab [11]. This is in sharp contrast to the fact that in most populationbased studies, the outcome is still poor, especially among older age groups $[2,5,6,8,23,30]$. In Sweden, there was no sign that new treatment options had translated into general survival improvements in a population-based study covering 2000-2013 [8]. In the United States, data from two national databases examining survival trends over time showed that the survival rate has increased in younger patients, while the survival rate among the elderly population has not changed in the 40 years from 1970 to 2010 [23,30]. In the United States, the 5-year overall survival rate increased from 19\% in 1992-1994 to 30\% in 20042006 [4]. Also, in a population-based study from the Netherlands, the 5-year relative survival rate improved from $22 \%$ in $1989-1995$ to $56 \%$ in $2009-2015$ in patients under age 60 , but at ages over 70 , 
the corresponding rates were $3 \%$ and $6 \%$, respectively. The overall 5 -year age-adjusted survival rate increased from $11 \%$ in 1989-1995 to 30\% in 2009-2015 [6]. In Korea, the overall 5-year survival rate was $30 \%$ between 1999 and 2007. Among patients aged 50 and younger (children included), the rate was 40\%, and at ages older than 70 , the corresponding rate was $4 \%$ [5]. Our results seem to be in line with those from the United States and Korea, where we discovered a trend toward improved survival in later periods. The reason for this improvement is probably the increasing use of combination immunochemotherapy. However, this is only an assumption because we do not have exact data regarding the treatments given.

In several prospective clinical studies, the treatment results are clearly better compared to populationbased studies [11,13]. There may be several factors explaining this discrepancy. One is the fact that many PCNSL patients have poor performance status during diagnosis, which is usually an exclusion criterion in prospective clinical studies. Elderly patients are also rarely included. Because age and performance status are the most important prognostic factors, this means that most prospective trials recruit only the cases with the most favorable prognosis. Another possible reason for the discrepancy is that in contrast to other aggressive lymphomas, PCNSL is a disease that may relapse many years after the diagnosis $[31,32]$. In a Finnish retrospective study, the long-term results for immunochemotherapy-treated PCNSL patients showed a constant pattern of relapse. Though demonstrating a favorable 2-year progression-free survival rate of $53 \%$, after longer follow-up period, only 1 patient out of 54 remained in remission at 60 months [31]. This was discovered also in a Japanese study with a follow-up for 14 years [33]. Because prospective trials are usually reported with limited follow-up time, a considerable number of patients will relapse after follow-up. Getting reliable insight into treatment efficacy at a 10-year follow-up, at least, is mandatory. In a population-based setting, new treatment options have not yet translated into major general survival improvements, although the presence of long-term survivors among fit patients is encouraging.

\section{Conclusions}

This study provides the first population-based estimates of PCNSL incidence and survival rates in Finland. A higher PCNSL incidence in comparison to other Nordic and European countries was discovered, which is unlikely to be caused by population growth or improved diagnostics. The change in age distribution towards older age may explain part of this. We found minor improvements in PCNSL survival during the study period, probably due to improved treatment options, although the survival of aged patients is still dismal.

We discovered a high incidence rate, but if some systemic error exists, we consider it would more likely be an underestimation than an overestimation. To get reliable data, we focused only on patients with diffuse large B-cell lymphoma, which excludes the few cases with miscellaneous histologies. Only biopsy-proven cases were included, and the fact that all aged patients with a declining physical performance status will not proceed to diagnostic biopsy would further underestimate the incidence rate. There is also a chance that the difference in survival rates between the time periods is due to random variation. 


\section{Declarations}

Acknowledgment: The authors wish to give special thanks to the Finnish National Cancer Registry for the data on PCNSL incidence and survival.

Compliance with ethical standards.

Declarations of interests: none.

\section{Funding}

The data were received from the FCR without any costs.

\section{Conflicts of interests/Competing interests}

There are no conflicts of interests.

\section{Availability of data and material}

FCR delivered the material.

\section{Code availability}

Not applicable.

\section{Authors' contributions}

Partial financial support was received from Pohjois-Suomen terveydenhuollon tukisäätiö (TERTTU foundation) [15] for the preparation of the article. It did not have any role in study design, collection or analysis of the data, writing of the report or the decision to submit the article for publication.

\section{Ethics approval}

All the study data were extracted with fully anonymized form. For these reasons, according to Finnish laws, no approval from an ethical committee was warranted.

\section{Consent to participate}

Not applicable.

\section{Consent for publication}

Not applicable.

\section{References}


[1] Dandachi D, Ostrom QT, Chong I, Serpa JA, Giordano TP, Kruchko C et al. Primary central nervous system lymphoma in patients with and without HIV infection: a multicenter study and comparison with U.S national data. Cancer Causes Control 2019;30:477-488.

[2] Haldorsen IS, Krossnes BK, Aarseth JH, Scheie D, Johannesen TB, Mella O et al. Increasing incidence and continued dismal outcome of primary central nervous system lymphoma in Norway 1989-2003 : time trends in a 15-year national survey. Cancer 2007;110:1803-1814.

[3] Krogh-Jensen M, D'Amore F, Jensen MK, Christensen BE, Thorling K, Pedersen M et al. Clinicopathological features, survival and prognostic factors of primary central nervous system lymphomas: trends in incidence of primary central nervous system lymphomas and primary malignant brain tumors in a well-defined geographical area. Population-based data from the Danish Lymphoma Registry, LYFO, and the Danish Cancer Registry. Leuk Lymphoma 1995;19:223-233.

[4] Shiels MS, Pfeiffer RM, Besson C, Clarke CA, Morton LM, Nogueira L et al. Trends in primary central nervous system lymphoma incidence and survival in the U.S. Br J Haematol 2016;174:417-424.

[5] Shin SH, Jung KW, Ha J, Lee SH, Won YJ, Yoo H. Population-based Incidence and Survival for Primary Central Nervous System Lymphoma in Korea, 1999-2009. Cancer Res Treat 2015;47:569-574.

[6] van der Meulen M, Dinmohamed AG, Visser O, Doorduijn JK, Bromberg JEC. Improved survival in primary central nervous system lymphoma up to age 70 only: a population-based study on incidence, primary treatment and survival in the Netherlands, 1989-2015. Leukemia 2017;31:1822-1825.

[7] Pulido JS, Vierkant RA, Olson JE, Abrey L, Schiff D, O'Neill BP. Racial differences in primary central nervous system lymphoma incidence and survival rates. Neuro Oncol 2009;11:318-322.

[8] Eloranta S, Branvall E, Celsing F, Papworth K, Ljungqvist M, Enblad G et al. Increasing incidence of primary central nervous system lymphoma but no improvement in survival in Sweden 2000-2013. Eur J Haematol 2018;100:61-68.

[9] Deckert M, Engert A, Bruck W, Ferreri AJ, Finke J, Illerhaus G et al. Modern concepts in the biology, diagnosis, differential diagnosis and treatment of primary central nervous system lymphoma. Leukemia 2011;25:1797-1807.

[10] Martinez-Calle N, Poynton E, Alchawaf A, Kassam S, Horan M, Rafferty M et al. Outcomes of older patients with primary central nervous system lymphoma treated in routine clinical practice in the UK: methotrexate dose intensity correlates with response and survival. $\mathrm{Br} J$ Haematol 2020;.

[11] Ferreri AJ, Cwynarski K, Pulczynski E, Ponzoni M, Deckert M, Politi LS et al. Chemoimmunotherapy with methotrexate, cytarabine, thiotepa, and rituximab (MATRix regimen) in patients with primary CNS lymphoma: results of the first randomisation of the International Extranodal Lymphoma Study Group-32 (IELSG32) phase 2 trial. Lancet Haematol 2016;3:217. 
[12] Phillips EH, Fox CP, Cwynarski K. Primary CNS lymphoma. Curr Hematol Malig Rep 2014;9:243-253.

[13] Schlegel U, Pels H, Glasmacher A, Kleinschmidt R, Schmidt-Wolf I, Helmstaedter C et al. Combined systemic and intraventricular chemotherapy in primary CNS lymphoma: a pilot study. J Neurol Neurosurg Psychiatry 2001;71:118-122.

[14] Finnish Cancer Registry [Internet]. Helsinki, Finland; 2021 [cited 2021 Jan 30]. Available from: https://cancerregistry.fi/

[15] Pohjois-Suomen terveydenhuollon tukisäätiö [Internet]. Oulu, Finland; 2021 [cited 2021 Feb 8]. Available from: https://terttusaatio.fi

[16] Cancer Society of Finland [Internet]. Helsinki, Finland; 2021 [cited 2021 Jan 30]. Available from: https://www.cancersociety.fi/

[17] Finnish Institute for Health and Welfare [Internet]. Helsinki, Finland; 2021 [cited 2021 Jan 30]. Available from: https://thl.fi/en/web/thlfi-en

[18] Leinonen MK, Rantanen M, Pitkaniemi J, Malila N. Coverage and accuracy of myeloproliferative and myelodysplastic neoplasms in the Finnish Cancer Registry. Acta Oncol 2016;55:782-786.

[19] Danckert B, Ferlay J, Engholm G , Hansen HL, Johannesen TB, Khan S, Køtlum JE, Ólafsdóttir E, Schmidt LKH, Virtanen A and Storm HH. NORDCAN: Cancer Incidence, Mortality, Prevalence and Survival in the Nordic Countries, Version 8.2 (26.03.2019). 2020.

[20] Engholm G, Ferlay J, Christensen N, Bray F, Gjerstorff ML, Klint A et al. NORDCAN--a Nordic tool for cancer information, planning, quality control and research. Acta Oncol 2010;49:725-736.

[21] Brenner $\mathrm{H}$, Hakulinen T. Long-term cancer patient survival achieved by the end of the 20th century: most up-to-date estimates from the nationwide Finnish cancer registry. Br J Cancer 2001;85:367-371.

[22] Brenner H, Soderman B, Hakulinen T. Use of period analysis for providing more up-to-date estimates of long-term survival rates: empirical evaluation among 370,000 cancer patients in Finland. Int $J$ Epidemiol 2002;31:456-462.

[23] Mendez JS, Ostrom QT, Gittleman H, Kruchko C, DeAngelis LM, Barnholtz-Sloan JS et al. The elderly left behind-changes in survival trends of primary central nervous system lymphoma over the past 4 decades. Neuro Oncol 2018;20:687-694.

[24] Statistics Finland. Population of Finland in 2007 [Internet]. Statistics Finland; Helsinki, Finland; 2008 March 28 [cited 2021 Jan 30]. Available from: https://www.stat.fi/til/vaerak/2007/vaerak_2007_2008-0328_tie_001_en.html 
[25] Statistics Finland. Population of Finland in 2017 [Internet]. Statistics Finland; Helsinki, Finland; 2018 March 29 [cited 2021 Jan 30]. Available from: https://www.stat.fi/til/vaerak/2017/vaerak_2017_2018-0329_tie_001_en.html

[26] Velasco R, Mercadal S, Vidal N, Alana M, Barcelo MI, Ibanez-Julia MJ et al. Diagnostic delay and outcome in immunocompetent patients with primary central nervous system lymphoma in Spain: a multicentric study. J Neurooncol 2020;.

[27] Finnish Institute of Health and Welfare. Statistical database of the National Infectious Diseases Register. 2020.

[28] Locke AE, Steinberg KM, Chiang CWK, Service SK, Havulinna AS, Stell L et al. Author Correction: Exome sequencing of Finnish isolates enhances rare-variant association power. Nature 2019;575:E4-X.

[29] Ponzoni M, Issa S, Batchelor TT, Rubenstein JL. Beyond high-dose methotrexate and brain radiotherapy: novel targets and agents for primary CNS lymphoma. Ann Oncol 2014;25:316-322.

[30] Furst T, Hoffman H, Chin LS. All-cause and tumor-specific mortality trends in elderly primary central nervous system lymphoma (PCNSL) patients: a surveillance, epidemiology, and end results (SEER) analysis. J Neurosurg Sci 2019;

[31] Harjama L, Kuitunen H, Turpeenniemi-Hujanen T, Haapasaari KM, Leppa S, Mannisto S et al. Constant pattern of relapse in primary central nervous lymphoma patients treated with high-dose methotrexate combinations. A Finnish retrospective study. Acta Oncol 2015;54:939-943.

[32] Biccler JL, Savage KJ, Brown PDN, Jorgensen J, Larsen TS, Poulsen CB et al. Risk of death, relapse or progression, and loss of life expectancy at different progression-free survival milestones in primary central nervous system lymphoma. Leuk Lymphoma 2019;60:2516-2523.

[33] Yamanaka R, Morii K, Shinbo Y, Sano M, Homma J, Tsuchiya N et al. Late relapse of primary central nervous system lymphoma. Leuk Lymphoma 2017;58:475-477.

\section{Figures}




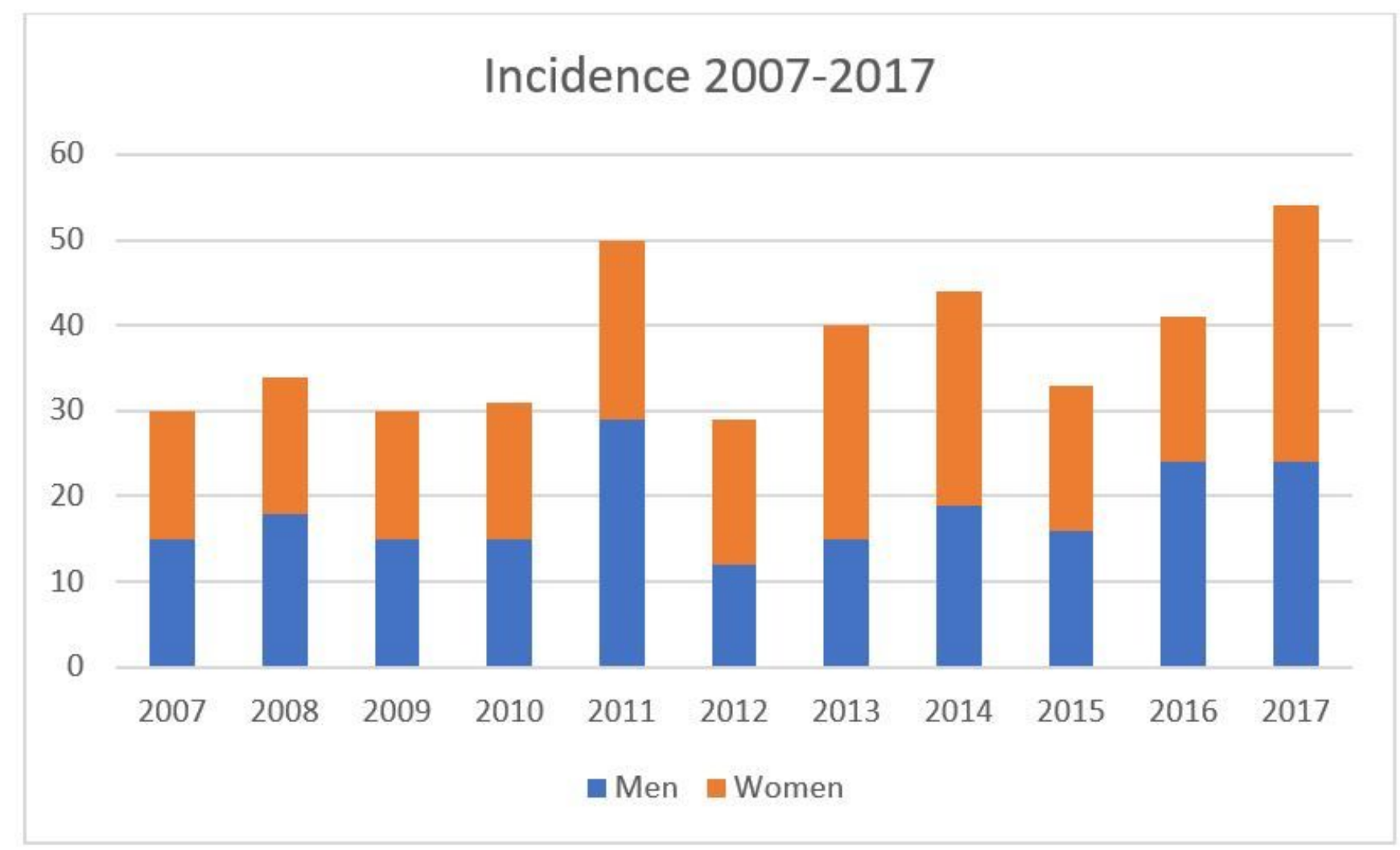

Figure 1

Primary central nervous system lymphoma (PCNSL) incidence in Finland for 2007-2017, cases per year. 


\section{Age-adjusted new cases and incidence 2007-2017}

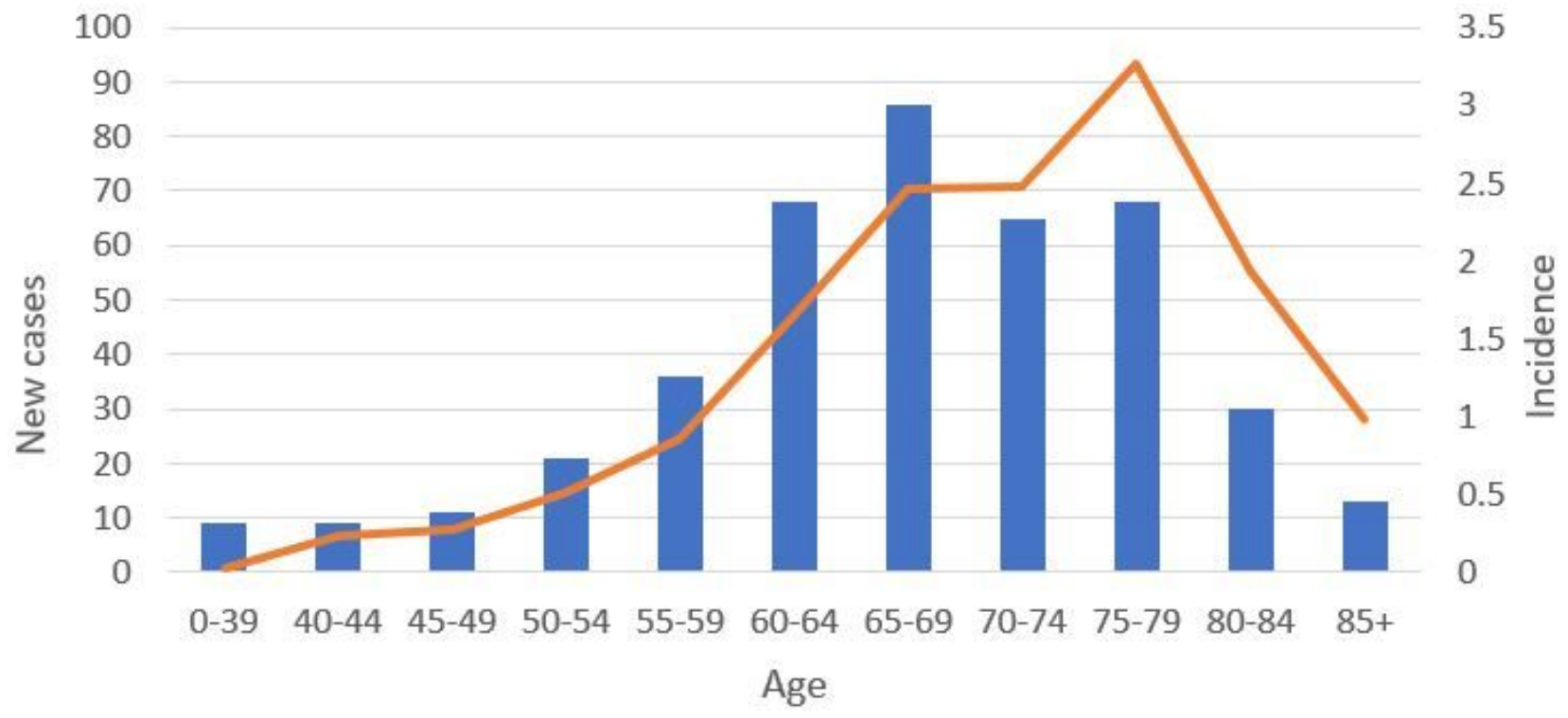

New cases Incidence

\section{Figure 2}

Number of age-adjusted new cases and incidence rates of primary central nervous system lymphoma (PCNSL) according to age.
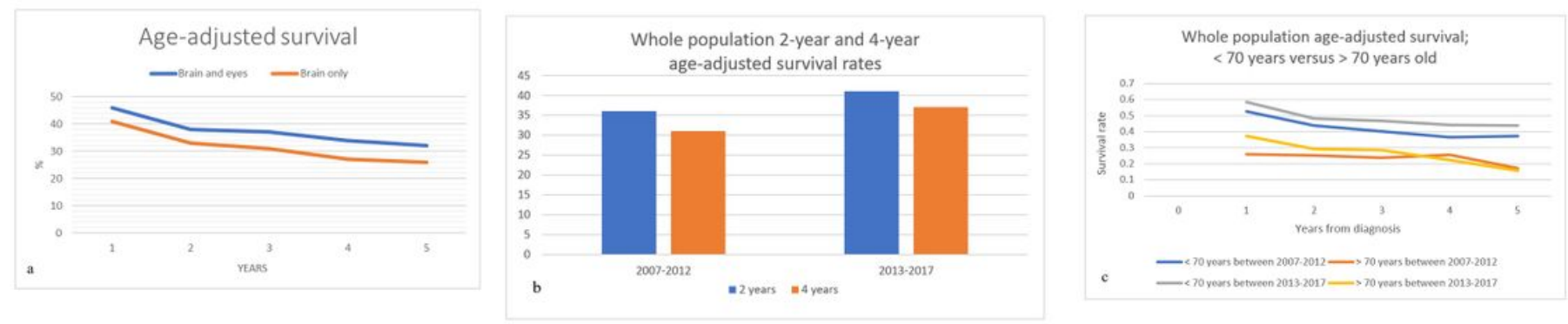

\section{Figure 3}

a) Age-adjusted survival rate for all cases and the cases with brain involvement only. b) Age-adjusted 2and 4-year survival rates between 2007-2012 and 2013-2017 (all cases). c) Age-adjusted survival curve according to the age and time of diagnosis (all cases). 